\title{
Data Modelling in Architecture: Digital Architectural Representations
}

Elisabetta Caterina Giovannini

\section{Abstract}

Digital Architectural Representations represent the most fruitful field of research of the last decade. Digital technologies and the use of internet in architectural representation shows how 3D visualization combined with storytelling can help to spread scientific knowledge over the web. These new technologies also affect the way of thinking 3D models, how to design them and how to build their related knowledge with the purpose of future reuse of information and data.

The paper is focused on the analysis of current methodologies and workflows for data modelling in Architecture to better understand the potential of using standards in the 3D modelling sector with a focus on cultural and architectural heritage.

Keywords

3D models, semantics, data models, standards, ontologies.

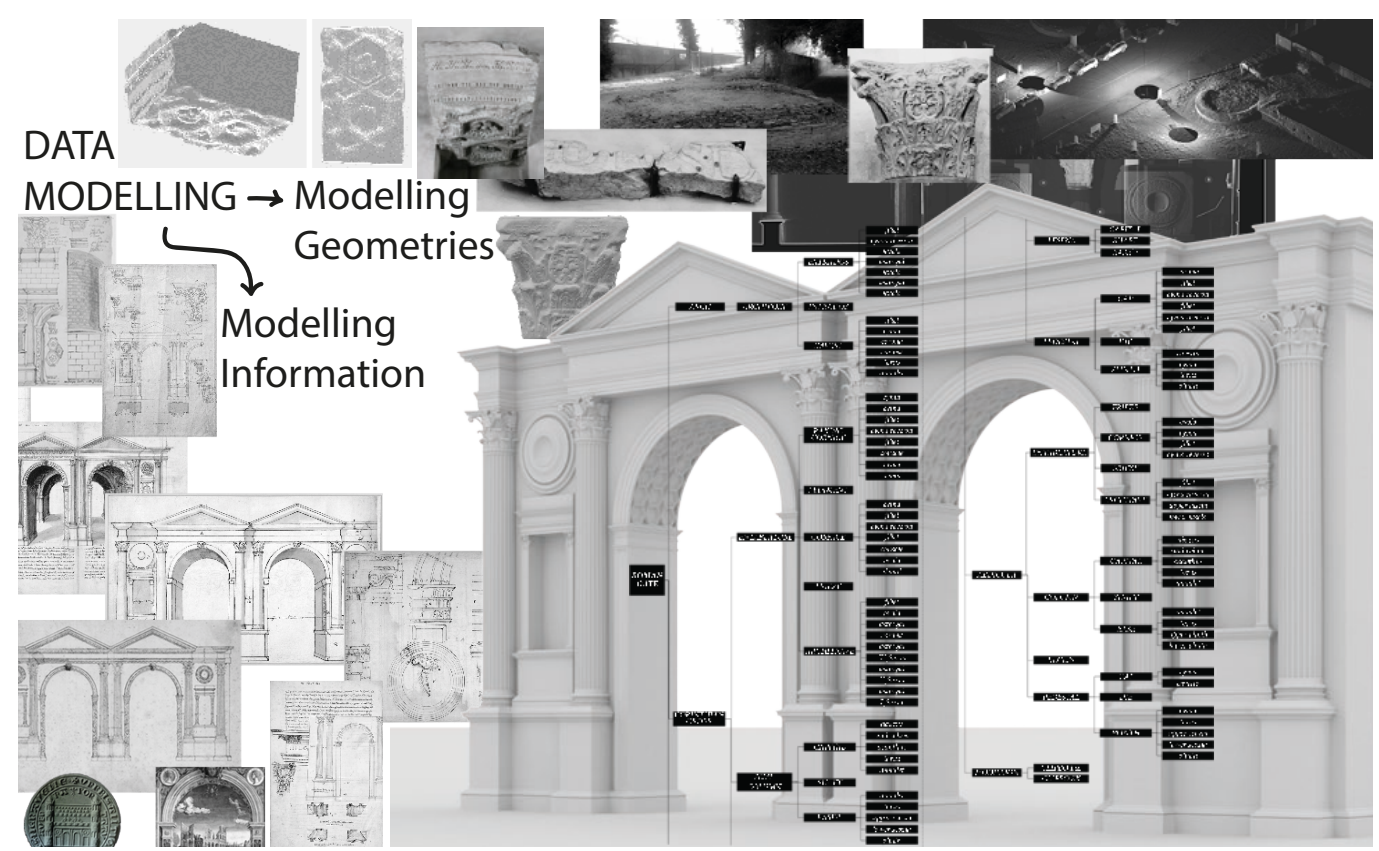




\section{The Complexity of Digital Architectural Representations}

Since the "90s of the last century, with the advent of computers, information technologies and computer-aided design (CAD) systems have seen the beginning of the use of digital models in archaeology and architecture [Boccon-Gibod, Golvin 1990; Frischer 2006; Reilly 199/]. The use of these three-dimensional models, which I like to define as digital representations of architecture, poses nowadays, unlike in the past, some questions about the meaning and the scientific value [Borra 2004; Borghini, Carlani 20 I I; Dell'Unto et al. 2013] that they assume for diverse target audiences.

In the field of architectural heritage and more specifically in the field of virtual reconstructions, starting from historical documentation, it seems evident that alongside geometric modelling, the presence of diverse data and documents prefigure the need for the definition on an informative model that should assist the geometric modelling and that should make explicit the series of processes related to the critical interpretation of data and information available [McCurdy 20I0; Apollonio, Giovannini 20I5; Brunke 2017]. Different interpretative and cognitive processes can be considered similar to algorithms "a procedure used to return a solution to a question through a set of welldefined instructions" [Tedeschi, Andreani 20I4]. The difference from the mathematical algorithm definition is that, in this case, the set of instructions are generally not stated and that the interpretative algorithm can generate several outputs (diverse hypothetical reconstructions) starting from the same series of input (knowledge available).

A Three-dimensional model became then, a digital architectural representation of the $\mathrm{n}$ digital representations that can be generated by human processes of interpretation. Analyzing the type of input of the three-dimensional reconstruction process, we can see how these interpretative processes are linked to the qualitative and quantitative values of the available documentation. This type of data and information support both geometric and informative modelling, considered as two indivisible and inter-related components of the same process. An example of that is the common practice of using the semantic architectural structure to digitally create the parts of a 3D model according to logics proper of the architectural field and to use digital architectural elements as reference objects to connect additional information [De Luca 2013; Giovannini 2017; Quattrini, Battini, Mammoli 20 I8]. A digital architectural representation can be, then, considered as a visual and graphical expression of an interpretative activity and a constitutive element of knowledge production. This assumption is valid not only for 3D models but also for all human objects of production that can be manuscripts, sketches, drawings, maquettes, etc. These pre-existing data can then be used for information modelling and threedimensional modelling enriching diverse Levels of Knowledge (LoK).

\section{Knowledge Representation in Architecture}

Applications of Artificial Intelligence (Al) to Cultural Heritage $(\mathrm{CH})$ have been developed with a varying fortune to produce innovative tools for documenting, managing, and visiting cultural heritage. From the representation of cultural history, digital semantic archives, tools to support visitor's interpretation, augmented reality and robotics, the application of Al has been applied to the whole humanistic area. In the Architectural Heritage field, Al is commonly used for storytelling, restoration analysis and $3 \mathrm{D}$ model classification. $\mathrm{Al}$ is also used to develop ontologies [ I ] to allow computers to perform automated reasoning about data and information all over the world. Software Engineering, on the other hand, started to use conceptual modelling as a representation of a system to describe concepts. Tools for designing and creation of online visualization of data, according to the rules that govern the web in the past, and more recently the semantic-web cannot avoid the use of Information modelling to manage and structure data and information. In the case of digital architectural representations, the text analysis and the source where architecture is represented in a bi-dimensional way are enriched by three-dimensional information derived from the digital acquisition or three-dimensional modelling. The recent need 
Fig. I. Conceptual data modelling overview. On the top, conceptu modelling of $\mathrm{H}-\mathrm{BIM}$ bject classes using CRMa extension. On the top-right, resourcebased modelling processes using CHARM model. On the bottomright a conceptual mode for the reality-based $3 \mathrm{D}$ modelling process using CRMdig extension On the left, conceptual representation of nowledge in the Architectural field. for interoperable processes that characterize most of the research on documentation and representation of architectural heritage has emphasized the occurrence of various approaches. Some studies analyze conceptual modelling to define and reorganize the information and material available for the comprehensive use of a digital asset. The theme of processes in digital modelling is useful to trace choices, decisions on three-dimensional models using visualization codes [De Kramer 2020; Giovannini 2020; Apollonio, Gaiani, Sun 2013]. Declaring the accuracy or reliability of 3D models [Apollonio et al. 2017; Bianchini, Nicastro 2018] including those obtained using tools and algorithms (for example in the case of digital survey or photogrammetric acquisition) is a practice mostly used in approaches for geomatics and Building Information Modelling applied to Heritage (H-BIM) [Maiezza 2019; Garagnani 2013; Quattrini, Pierdicca, Morbidoni 2017]. Resource-based 3D modelling considered as interpretative process, differs from digital acquisition where reality-based data can be considered as formal derivation of the original object. Both modelling processes are in relation since the 3D reality-based data, if present, affects the modelling and validation process of the derived resource-based model. Standards and models for information modelling including conceptual ones have long been in use in the cultural heritage sector: the CIDOC Conceptual Reference Model (CRM) standard [2], the ISO 2 I 127:2014 also known as CIDOC-CRM, often associated with the controlled vocabulary of the Getty Institute (AAT) [3], is the most used ones. Recent trends demonstrate that ontologies and conceptual models are not that different,

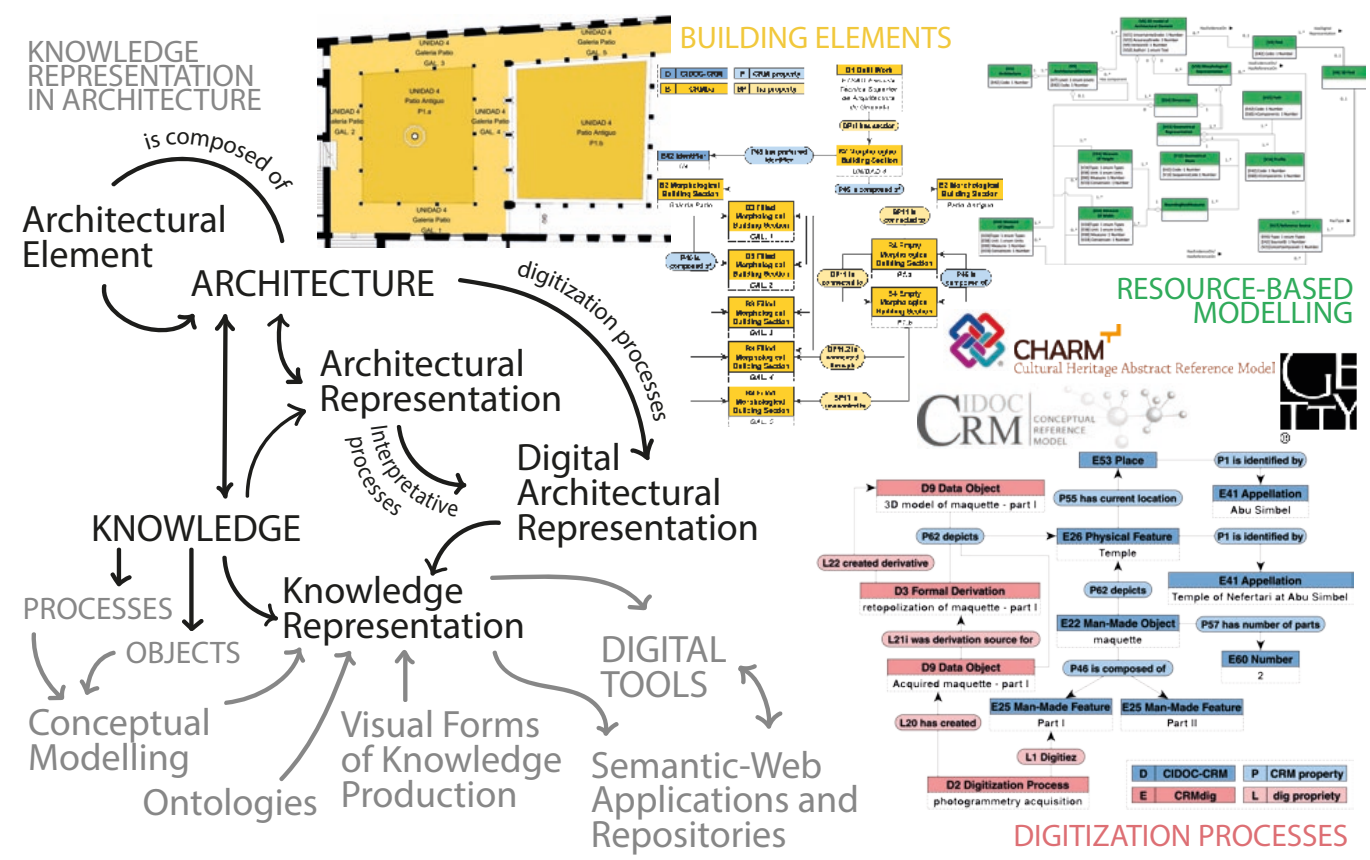

and that combined can allow standardising the documentation of cultural heritage. In the archaeological field the Cultural Heritage Abstract Reference Model (CHARM) [4] is an ontology for cultural heritage expressed in Conceptual Modelling Language (ConML) [Gonzalez-Perez et al. 20 I2].The Extended Matrix (EM) [5] is a visual language of knowledge representation in the field of virtual reconstructions with a stratigraphic approach [Demetrescu 2015]. In the architecture, engineering and construction (AEC) industry, the reference standard is the Industry Foundation Classes (IFC) data model [6], a metadata schema capable of describing architectural semantics and making Building Information Modelling (BIM) models interoperable between different software solutions. The IFC guarantees the management of geometry but it does not allow the addition of customized information outside the context of the construction industry. Nevertheless, some emerging research proposes an IFC classification for architectural heritage asset 
[Diara, Rinaudo 2020] or an architectural heritage semantic 3D documentation for the reusability of $3 \mathrm{D}$ city models [Noardo 20I8]. To establish a dialogue between the architectural field and the cultural heritage assets a recent study proposes a conceptual model based on the CIDOC-CRM standard to describe a building in its parts, as encoded by a BIM software using the CIDOC-CRMba extension [7], developed to describe built archaeology [Parisi, Lo Turco, Giovannini 2019]. With that model, it was possible to describe the morphological elements that characterize a building but it fails in describing the link between the geometric parts and their spatial coordinates. The conclusion was partially acceptable if we think that the CIDOC-CRM was born to describe assets about museum collections and not about architecture.

\section{Conclusions}

Considering the diverse research conducted, the possibility of creating conceptual models capable of managing three-dimensional data and descriptive metadata on the documentation of architectural heritage is still missing. The CRM-dig [8], a CIDOCCRM extension, is a model capable to manage the complexity of the reality-based data acquisition, but it does not clarify and explain the relationships between the source used, the data extracted from it and its use for geometrical modelling. The IFC, on the other hand, can be used to describe geometric information of BIM or $\mathrm{H}-\mathrm{BIM}$ models. The challenge is to create an efficient data model that allows semantic traceability of data. A novel semantic organization of data is necessary for the development, of platforms, analysis tools and algorithms able to manage structured data, make queries for different purposes in complementary disciplinary domains emphasising their combined potential. There is a need for a common conceptual model that reflects the complexity of the threedimensional modelling process. Conceptual modelling should focus on the representation of architecture in all its forms (drawings, surveys, digital models) and should represent both digital and physical properties. A conceptual reference model for the digital representation of architecture (fig. I) should first identify the architectural evidence, built, or only represented ones, the parts of which it can be composed and how these can be digitally represented. The knowledge about an architectural asset is also composed of a set of resources that also need to be digitized and that contribute to the creation of the "architectural" digital asset. Then the relationship between digitized resources and threedimensional modelling can take place by mapping diverse interpretative and modelling processes creating different levels of knowledge. The knowledge produced, can then be used by digital tools able to read the conceptual grammar of the asset: an information system in which three-dimensional models and historical documentation is collected and organized. To reuse data, data models are necessary and even if they do not follow standards, they must at least be stated because this is how computational technologies and machine can see the human world.

\section{Notes}

[I] Ontology is the theory and the Information Model is the application. Information modelling is here intended as "a representation of concepts, relationships, constraints, rules, and operations to specify data semantics for a chosen domain of discourse. The advantage of using an information model is that it can provide sharable, stable, and organized structure of information requirements for the domain context." [Lee 1999]

[2] The CIDOC Conceptual Reference Model (CRM). http://www.cidoc-crm.org/ (March 202I)

[3] Art \& Architecture Thesaurus (AAT) - Getty Research Institute. https:/wnw.getty.edu/research/tools/vocabularies/aat/ (March 2021)

[4] Cultural Heritage Abstract Reference Model (CHARM) - INCIPIT, CSIC. www.charminfo.org (March 202I)

[5] The Extended Matrix formal language for virtual reconstruction processes. http://osiris.itabc.cnr.it/extendedmatrix/ (March 202I)

[6] Industry Foundation Classes. https://umw.buildingsmart.org/standards/bsi-standards/industry-foundation-classes/ (March 202I)

[7] An extension of CIDOC CRM to support buildings archaeology documentation. http://www.cidoc-crm.org/crmba/ (March 202I)

[8] An extension of CIDOC CRM to encode "provenance" of digitization products. http://www.cidoc-crm.org/crmdig/ (March 202I) 


\section{References}

Apollonio Fabrizio I., Fallavollita Federico, Giovannini Elisabetta C., Foschi Riccardo, Corso Salvatore (20 I7). The Reconstruction of Drawn Architecture. In Studies in Digital Heritage, I, 20 I7, pp. 380-395.

Apollonio Fabrizio I., Gaiani Marco,Sun Zheng (20 I3). Characterization of Uncertainty and Approximation in Digital Reconstruction of Ch Artifacts. In Proceeding of Le Vie dei Mercanti XI Forum Internazionale di Studi, pp. 860-869.

Apollonio Fabrizio I., Giovannini Elisabetta C. (20 I 5). A Paradata Documentation Methodology for the Uncertainty Visualization in Digital Reconstruction of Ch Artifacts. In SCIRES-IT-SClentific RESearch and Information Technology, 5 ( I), pp. I-24.

Bianchini Carlo, Nicastro Saverio (2018). The definition of the Level of Reliability: a contribution to the transparency of HeritageBIM processes. In Dn-Building Information Modeling, Data \& Semantics, 2, pp. $45-49$.

Boccon-Gibod Par H., Golvin Jean-Claude (1990). Le Grand Temple d'Amon Rê a Karnak Reconstruit Par l'ordinateur. In Les Dossiers d'Archeologie, 153, pp. 8-19.

Borghini Stefano, Carlani Raffaele (20II). Virtual rebuilding of ancient architecture as a researching and communication tool for Cultural Heritage: aesthetic research and source management. In DISEGNARECON, 4 (8), pp. 7I-79.

Borra Davide (2004). Sulla Verità Del Modello 3D. Un Metodo per Comunicare La Validità Dell'anastilosi Virtuale." In EArcom04 Tecnologie per Comunicare l'architettura. Proceeding of the eArcom 4, pp. I32- 137.

Brunke Luca (2017). Uncertainty in Archaeological 3D Reconstructions. Master Thesis, University of Leiden.

Dell'Unto Nicolò, Leander Anne-Marie, Dellepiane Matteo, Callieri Marco, Ferdani Daniele, Lindgren Stefan (20।3). Digital reconstruction and visualization in Archaeology: case-study drawn from the work of the Swedish Pompeii Project. In Proceedings of the DigitalHeritage, I, pp. 621-628.

Demetrescu Emanuel (20 I5). Archaeological Stratigraphy as a Formal Language for Virtual Reconstruction. Theory and Practice. In Journal of Archaeological Science, 57, pp. 42-55.

Diara Filippo, Fulvio Rinaudo (2020). IFC classification for FOSS HBIM: Open Issues and a schema proposal for Cultural Heritage assets. In Applied Sciences, 10 (23), pp. I-23.

Frischer Bernard (2006). New directions for cultural Virtual Reality: a global strategy for archiving, serving and exhibiting 3D computers models of Cultural Heritage sites. In Proceedings of the Virtual Retrospect 2005, pp. I 68- I 75.

Garagnani Simone (2013). Building Information Modeling and real world knowledge: a methodological approach to accurate semantic documentation for the Built Environment. In Proceedings of the DigitalHeritage, I, pp.489-496.

Giovannini Elisabetta C. (2020). Workflow for an evidence-based Virtual Reconstruction: the marbles of the Ciborium of the Early Medieval Monte Sorbo Church. In ISPRS Archives, 43, pp. I395- 1402.

Giovannini Elisabetta C. (2017).VRIMWorkflow: semantic H-BIM objects using parametric geometries. In EmplerTommaso (ed.) 3D MODELING \&BIM. Progettazione, Design, Proposte per La Ricostruzione. Roma: DEI Tipografia del Genio Civile, pp. $212-229$.

Gonzalez-Perez Cesar, Martín-Rodilla Patricia, Parcero-Oubiña Cesar, Fábrega-Álvarez Pastor, Güimil-Fariña Alejandro (20 I2). Extending an abstract reference model for transdisciplinary work in Cultural Heritage. In Dodero Juan Manuel, Palomo-Duarte Manuel, Karampiperis Pythagoras (eds.). Metadata and Semantics Research. Berlin, Heidelberg: Springer, pp. 190-201.

De Luca Livio (20 I3). 3D Modeling and Semantic Enrichment in Cultural Heritage. In Dieter Fritsch (ed.). Photogrammetric Week. Berlin:Wichmann Verlag, pp. 323-333.

De Kramer Marleen (2020). Relict-Interpolated-Extrapolated-Speculative: an approach to degrees of Accuracy inVirtual Heritage Reconstruction. In Fotis Liarokapis, Athanasios Voulodimos, Nikolaos Doulamis, Anastasios Doulamis (eds.). Visual Computing for Cultural Heritage. Cham: Springer International Publishing, pp. 409-422.

Lee Y. Tina (1999). Information Modeling: from design to implementation. In Proceedings of the Second World Manufacturing Congress, pp. 315-321.

Maiezza Pamela (2019). As-built reliability in architectural HBIM modeling. In ISPRS Archives, 42, pp. 46I-466.

McCurdy Leah (2010). Visualising Architecture:The Experience of Creating Virtual Reconstructions. Master Thesis, University of York.

Noardo Francesca (20 18). Architectural Heritage Semantic 3D Documentation in Multi-Scale Standard Maps. In Journal of Cultural Heritage, 32, pp. $156-165$.

Parisi Piergiorgio, Lo Turco Massimiliano, Giovannini Elisabetta C. (2019). The value of knowledge through H-BIM models: historic documentation with a sematic approach. In ISPRS Archives, 42, pp. 58I-588.

Quattrini Ramona, Battini Carlo, Mammoli Raissa (2018). HBIM to VR. Semantic Awareness and Data Enrichment Interoperbility for Parametric Libraries of Historical Architecture. In ISPRS Archives, 42 (2), pp. 937-943

Quattrini, Ramona, Roberto Pierdicca, and Christian Morbidoni (2017). Knowledge-Based data enrichment for HBIM: exploring high-quality Models Using the Semantic-Web. In Journal of Cultural Heritage, 28, pp. I 29- I 39.

Reilly Paul (199|). Towards a Virtual Archaeology. In Proceeding of the CAA90. Computer Applications and Quantitative Methods in Archaeology 1990, pp. 132-139.

Tedeschi Arturo (20|4). AAD, Algorithms-Aided Design: Parametric Strategies Using Grasshopper. Brienza: Le Penseur Publisher.

\section{Author}

Elisabetta Caterina Giovannini, Dept. of Architecture and Design, Politecnico di Torino, elisabettacaterina.giovannini@polito.it 
